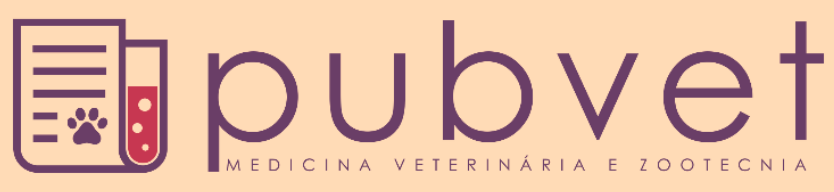

https://doi.org/10.31533/pubvet.v13n7a382.1-11

\title{
Melhoramento genético de plantas forrageiras xerófilas: Revisão
}

\author{
Isaias Vitorino Batista de Almeida ${ }^{1 *} \bullet$, José Thyago Aires $\operatorname{Souza}^{2} \bullet$, Mateus Costa Batista ${ }^{\natural}$ \\ ${ }^{1}$ Pesquisador da Empresa Paraibana de Pesquisa, Extensão Rural e Regularização Fundiária (EMPAER), Estação \\ Experimental Pendência, Soledade-PB, Brasil. \\ ${ }^{2}$ Universidade Federal da Paraíba (UFPB), programa de pós-graduação em Agronomia, Areia-PB, Brasil. \\ ${ }^{3}$ Doutorando em Engenharia Agrícola, Universidade Federal de Campina Grande, Brasil. \\ *Autor para correspondência, E-mail: isaiasvba@gmail.com
}

Resumo. A precipitação é a principal variável climática para o Semiárido brasileiro, sendo um fator limitante para produção de vegetais, principalmente em regiões com histórico de ocorrência de baixas pluviosidades. Por outro lado, a pecuária é a principal atividade econômica dessa região e a produção de alimento para os animais, infelizmente, ainda se constitui no maior gargalo. A presente revisão tem como objetivo principal descrever o melhoramento genético das principais plantas forrageiras xerófilas cultivadas no Semiárido brasileiro e das espécies com potencial de cultivo para as áreas com registro histórico de baixas precipitações. As espécies discriminadas são: palma forrageira, capim buffel, algodão mocó, flor-de-seda, mandacarú, feijão-bravo e maniçoba. O programa de melhoramento genético dessas espécies se inicia com a formação de um banco ativo de germoplasma (BAG) e compreende a realização de diferentes estratégias, como a domesticação da espécie, que envolve o cultivo, avaliação, caracterização agronômica e bromatológica dos acessos, estudo de diversidade genética, seleção de plantas, hibridação, alteração cromossômica, uso de ferramentas de biotecnologia, entre outras estratégias. A execução de programas de melhoramento genético dessas culturas xerófilas torna-se uma ferramenta necessária para cultivo, domesticação de materiais silvestres e obtenção de novas variedades, com maior potencial de produção e com a função de elevar a renda das propriedades rurais do Semiárido brasileiro.

Palavras chave: domesticação, pecuária, semiárido, seleção de genótipos

\section{Genetic improvement of xerophilic forage plants: Review}

\begin{abstract}
Precipitation is the main climatic variable for the Brazilian semi-arid region, being a limiting factor for vegetable production, especially in regions with low rainfall. On the other hand, livestock farming is the main economic activity of this region and the production of food for animals, unfortunately, still constitutes the biggest bottleneck. The main objective of this review is to describe the genetic improvement of the main xerophilic forage plants cultivated in the Brazilian semi-arid region and of the species with potential for cultivation in areas with low rainfall records. The species described are: (Opuntia cochenillifera), buffel grass (Cenchrus Ciliaris L), cotton mocó mocó (Gossypium hirsutum L), silk flower, (Calotropis procera (Ait.) W.T. Aiton), Cereus jamacaru and Manihot. The genetic breeding program of these species begins with the formation of an active germplasm bank (AGB) and includes the realization of different strategies, such as the domestication of the species, which involves the cultivation, evaluation, agronomic and bromatological characterization of the accesses, study of genetic diversity, plant selection, hybridization, chromosomal alteration, use of biotechnology tools, among other strategies. The execution of genetic improvement programs of these xerophytic cultures becomes a necessary tool for cultivation, domestication of wild materials and obtaining new varieties,
\end{abstract}


with greater potential of production and with the function of raising the income of the rural properties of the Brazilian semi-arid.

Keywords: domestication, livestock, semi-arid, genotype selection

\section{Mejoramiento genético de plantas forrajeras xerófilas: Revisión}

Resumen La precipitación es la principal variable climática para el semiárido brasileño, siendo un factor limitante para la producción de plantas, especialmente en regiones con un historial de bajas precipitaciones. Por otro lado, el ganado es la principal actividad económica de esta región y, lamentablemente, la producción de alimentos para animales sigue siendo el mayor cuello de botella. El objetivo principal de esta revisión es describir la mejora genética de las principales plantas forrajeras xerófilas cultivadas en la región semiárida brasileña y las especies con potencial de cultivo en áreas con un registro histórico de baja precipitación. Las especies discriminadas son: palma forrajera (Opuntia spp.), pasto buffel (Cenchrus Ciliaris L), algodón mocó (Gossypium hirsutum L), flor de seda (Calotropis procera (Ait.) W.T. Aiton), mandacarú (Cereus jamacaru P. DC.), frijol silvestre y maniçoba (Manihot ssp.). El programa de reproducción de estas especies comienza con la formación de un banco de germoplasma activo (BAG) y comprende la implementación de diferentes estrategias, como la domesticación de la especie, que implica el cultivo, la evaluación, la caracterización agronómica y bromatológica de las accesiones. diversidad genética, selección de plantas, hibridación, alteración cromosómica, uso de herramientas biotecnológicas, entre otras estrategias. La ejecución de programas de mejora genética de estos cultivos xerófilos se convierte en una herramienta necesaria para el cultivo, la domesticación de materiales silvestres y la obtención de nuevas variedades, con mayor potencial de producción y con la función de aumentar los ingresos de las propiedades rurales de la región semiárida brasileña.

Palabras clave: domesticación, ganadería, semiárido, selección de genotipos

\section{Introdução}

O termo "xerófita" foi introduzido por Warming em 1895 para caracterizar plantas que conseguem viver em ambientes áridos, ou seja, que completam seu ciclo vital em regiões carentes de água. A palavra "xerófita" é usada para designar "plantas resistentes à seca", sendo um o termo genérico que caracteriza os diferentes mecanismos encontrados nas plantas superiores que representam a resposta evolutiva do vegetal à pressão de seleção exercida pela seca. Existem, basicamente, três mecanismos: fuga à seca ou plantas efêmeras, tolerância à seca em altos níveis negativos de potencial hídrico e tolerância à seca em baixos níveis de potencial hídrico (Prisco, 1986).

Para Duque (2004), as plantas xerófilas são aquelas que toleram a escassez d'água, que fogem aos efeitos da deficiência hídrica ou que resistem à seca. $\mathrm{O}$ autor define que elas podem ser classificadas em três tipos, conforme o modo como conseguem sobreviver: efêmeras, suculentas e lenhosas. As efêmeras são as plantas que aproveitam a estação chuvosa para completar todos os estádios fenológicos, cujo ciclo não ultrapassa algumas semanas ou meses. As suculentas são as cactáceas perenes a exemplo da palma forrageira e do mandacarú. As xerófilas lenhosas são as árvores e os arbustos, as plantas perenes e caducifólias, incluindo as plantas nativas da Caatinga. A principal planta xerófila cultivada no Semiárido brasileiro é a palma forrageira, pois a pecuária é a principal atividade econômica dessa região. Segundo Andrade et al. (2006), a produção de alimento para os animais, infelizmente, ainda se constitui no maior problema da pecuária no Semiárido, principalmente em regiões com baixa precipitação. Para criar bovinos, caprinos ou ovinos, de forma lucrativa, os agricultores familiares não poderão utilizar apenas as caatingas ou os pastos nativos, como únicos recursos forrageiros para garantir a manutenção de seus rebanhos. É necessário o cultivo de plantas adaptadas como forma de aumentar o suporte forrageiro (Lima et al., 2010). Nesse sentido, com vistas a tentar solucionar o problema alimentar dos rebanhos, sobretudo no período seco do ano, pesquisadores recomendam o cultivo de plantas forrageiras xerófilas, como forma de reduzir os riscos de perda da produção decorrentes das flutuações sazonais da precipitação (Andrade et al., 2010; Andrade et al., 2006; Duque, 2004). 
A precipitação é a principal variável climática para o Semiárido brasileiro, sendo um fator limitante para produção de vegetais, em virtude de ser altamente variável, imprevisível, onde comumente ocorre em eventos descontínuos, em forma de pulsos de relativa curta duração (Andrade et al., 2010). Historicamente é conhecida a existência das grandes secas no Nordeste, como também o insucesso no cultivo de culturas agrícolas. Nos últimos seis anos o Nordeste brasileiro passou por um dos maiores ciclos de seca da história, com precipitações anuais inferiores a $200 \mathrm{~mm}$ em alguns municípios; sendo o cultivo de plantas forrageiras xerófilas a principal estratégia de convivência com a seca, como forma de garantir produção de alimento volumoso nestes anos.

O sucesso no cultivo de uma espécie xerófila depende, primariamente, do material genético utilizado, principalmente com espécies não domesticadas a exemplo da flor-de-seda (Calotropis procera (Ait.) W.T. Aiton), do mandacarú (Cereus jamacaru P. DC.), do feijão-bravo (Capparis flexuosa L.) e da maniçoba (Manihot ssp.), sendo, portanto, necessário a condução de um programa de melhoramento genético da espécie, para a seleção de genótipos com maior potencial forrageiro.

Sendo assim, a presente revisão tem como objetivo principal descrever o melhoramento genético das principais plantas forrageiras xerófilas cultivadas no Semiárido brasileiro e das espécies com potencial de cultivo para as áreas com registro histórico de baixas precipitações.

\section{Melhoramento genético de plantas forrageiras xerófilas para o Semiárido brasileiro}

A presente revisão traz informações sobre as principais plantas forrageiras xerófilas cultivadas no Semiárido brasileiro e algumas etapas no programa de melhoramento genético de cada espécie, a exemplo da palma forrageira (Opuntia spp.) e do capim buffel (Cenchrus ciliaris L.), como também de espécies com potencial de serem cultivadas para produção de forragem, a exemplo do algodão mocó (Gossypium hirsutum L. r. marie galante Hutch), da flor-de-seda (Calotropis procera (Ait.) W.T. Aiton), do mandacarú (Cereus jamacaru P. DC.), feijão-bravo (Capparis flexuosa L.) e maniçoba (Manihot ssp.).

O melhoramento genético vegetal é a arte e ciência de aperfeiçoar o padrão genético de plantas em relação ao seu uso econômico, tendo como objetivos: selecionar e desenvolver plantas com maior potencial produtivo, para novas áreas agrícolas, para áreas desfavoráveis, materiais com redução de constituintes tóxicos, com resistência à pragas e doenças ou mesmo para condições de estresses abióticos, por exemplo, hídrico, salino, entre outras finalidades (Fritsche-Neto \& Borém, 2011). Para iniciar um programa de melhoramento genético de uma espécie de planta é necessário proceder a um planejamento do programa, ou seja, realizar, inicialmente, levantamento bibliográfico do que foi feito em programas semelhantes; levantamento do germoplasma existente no centro de origem da espécie; verificar o modo de reprodução da espécie; definir os objetivos e analisar os entraves para execução do programa (Fritsche-Neto \& Borém, 2011). Para haver o estabelecimento do programa de melhoramento genético, inicialmente, deve existir um banco ativo de germoplasma (BAG), que é uma coleção viva do patrimônio genético de uma espécie vegetal, que detém um número expressivo de acessos, incluindo materiais silvestres, genótipos crioulos, linhagens e cultivares (Costa et al., 2012; Fritsche-Neto \& Borém, 2011; Ramos et al., 2007). No caso de plantas não domesticadas, a exemplo da flor-de-seda, do mandacarú, feijão-bravo e maniçoba a formação do BAG consiste apenas de plantas silvestres. $\mathrm{O}$ objetivo central dos bancos de germoplasma é a conservação dos recursos genéticos vegetais visando preservar a variabilidade genética das espécies, podendo ser utilizados nos programas de melhoramento genético de plantas. Em geral, o programa de melhoramento possui etapas distintas, que envolve avaliação e caracterização agronômica dos acessos do BAG, estudo de diversidade genética, seleção de plantas, hibridação, alteração cromossômica, uso de ferramentas de biotecnologia, entre outras estratégias (Costa et al., 2012; Fritsche-Neto \& Borém, 2011; Ramos et al., 2007). A execução do programa de melhoramento genético de plantas não é uma tarefa fácil, demanda tempo, possui custos elevados até atingir a função principal do programa que é proceder ao registro de cultivares. Dessa forma, recomenda-se o desenvolvimento de um programa de melhoramento genético com espécies xerófilas forrageiras domesticadas ou com potencial de domesticação a exemplo da flor-de-seda, visto ter características agronômicas favoráveis, como potencial fisiológico de sementes, crescimento e produção de fitomassa. 
A escolha da planta forrageira xerófila para cultivo no Semiárido brasileiro, principalmente para as áreas com registro histórico de baixas precipitações, deve ser com base na capacidade do vegetal em resistir à seca, na fenologia da espécie e por meio das características agronômicas e bromatológicas da espécie.

Com relação à capacidade do vegetal em resistir à seca, esta é uma característica essencial para o sucesso na atividade pecuária em propriedades rurais do Semiárido, visto que, historicamente se sabe da ocorrência de secas no Nordeste. Cultivar plantas com resistência comprovada a esse fenômeno é uma estratégia de convivência com a seca e uma tentativa de garantir produção de forragem mesmo nos anos com baixas precipitações.

As plantas com fenologia perenifólia, ou seja, que permanece verde ao longo de todo o ano, principalmente nos períodos mais secos do ano, torna-se uma opção importante de garantir produção de forragem, mesmo em anos com baixas precipitações, bem como favorece a colheita da fitomassa no período seco, época que o produtor rural tem baixo suporte forrageiro e necessita de forragem para suprir a dieta animal. São exemplos de plantas perenifólias: palma (Opuntia spp.), flor-de-seda (Calotropis procera (Ait.) W.T. Aiton), algodão mocó (G. hirsutum L, r marie galante Hutch), capim buffel (Cenchrus ciliaris L.), mandacarú (Cereus jamacaru P. DC.) e feijão-bravo (Capparis flexuosa L.). Além dessas, uma espécie que não é perene, mas que possui importância para pecuária do Semiárido brasileiro é a maniçoba (Manihot ssp.), devido, principalmente, a capacidade de rebrota em baixas precipitações e do teor de proteína bruta. Apesar de ser uma planta caducifólia, ou seja, que perde folhas quando o solo se encontra em déficit hídrico, a maniçoba será descrita na presente revisão como única espécie caduca indicada para domesticação, pois pode ser cultivada e fornecida como forragem conservada (feno e/ou silagem) no período de seca.

Com relação às características agronômicas, deve-se levar em consideração o potencial produtivo da cultura, o crescimento da espécie, o sistema radicular, o tipo de fotossíntese, o potencial fisiológico das sementes, entre outras características, que estão diretamente relacionadas com a capacidade de resistir às secas e ao tipo de manejo que será utilizado no sistema de produção. Além disso, é importante conhecer as características bromatológicas do vegetal, sobretudo, de uma espécie não domesticada, mas que possui potencial de cultivo.

\section{Mecanismos de resistência à seca das plantas forrageiras xerófilas}

A adaptação das plantas ao déficit hídrico é um mecanismo muito complexo, envolvendo fatores inerentes ao genoma da espécie, a mecanismos fisiológicos, bioquímicos e morfológicos do vegetal. Não é apenas um mecanismo que confere a planta capacidade de resistir à seca é a união de características que garantem às plantas sobrevivência aos ciclos de seca (Fritsche-Neto \& Borém, 2011; Simova-Stoilova et al., 2016).

O processo de evolução das plantas superiores à pressão de seleção exercida pela seca originou plantas com capacidade de síntese de moléculas importantes, que estão diretamente relacionadas com a resistência à seca, a exemplo do ácido abscísico (ABA), um metabólito secundário produzido em resposta a ocorrência de estresse hídrico. A síntese do ABA promove o fechamento dos estômatos, principal mecanismo de controle da transpiração e perda de água nos vegetais. Plantas com eficiência na síntese desse hormônio possuem maior capacidade de resistir aos efeitos do estresse hídrico(Kitahata et al., 2006; Seki et al., 2007; Taiz \& Zeiger, 2009). O ABA funciona como molécula sinalizadora do fechamento estomático, que desencadeia outras respostas nas plantas, relacionadas com mecanismos de resistência à seca, a exemplo da redução da atividade fotossintética, acúmulo de solutos no vacúolo (ajustamento osmótico), inibição do crescimento da parte aérea em detrimento da expansão do sistema radicular, senescência foliar, alteração na expressão gênica, tendo como consequência a redução da produção e da produtividade vegetal (Fritsche-Neto \& Borém, 2011; Seki et al., 2007; Taiz \& Zeiger, 2009).

Com relação ao mecanismo fisiológico é importante detalhar os tipos de metabolismo existentes em plantas superiores, ou seja, as plantas $\mathrm{C}_{3}, \mathrm{C}_{4}$ e CAM. As $\mathrm{C}_{3}$ são plantas que realizam a fixação de $\mathrm{CO}_{2}$ e sínteses de carboidratos durante o dia e nesse processo perdem água durante a transpiração (Taiz \& Zeiger, 2009), sendo uma característica desfavorável em plantas para cultivo em regiões com ocorrência de baixas precipitações. 
As plantas $\mathrm{C}_{4}$ possuem maior tolerância ao déficit hídrico, pois conseguem armazenar $\mathrm{CO}_{2}$ nas células do mesófilo e com isso reduzem a perda de água, quando comparado com as $\mathrm{C}_{3}$, devido à redução da abertura dos estômatos. Por fim, as plantas com fotossíntese do tipo CAM (crassulacean acid metabolism) realizam abertura dos estômatos e fixação de $\mathrm{CO}_{2}$ durante a noite, não ocorre transpiração de dia e com isso evitam à perda de água excessiva, a palma forrageira é um exemplo de planta CAM (Santos et al., 2017; Taiz \& Zeiger, 2009). Além disso, é importante destacar que existem plantas com fotossíntese intermediaria, realizam dois tipos de fotossíntese. Por exemplo, uma espécie pode ser do tipo $\mathrm{C}_{3}$ ou CAM, ou seja, em épocas sem ocorrência de déficit hídrico a planta possui metabolismo $\mathrm{C}_{3}$ e em períodos de seca passa a ser uma planta CAM, sendo outro mecanismo de resistir os efeitos do déficit hídrico. Outra característica fisiológica relacionada com a tolerância à seca é a magnitude do sistema antioxidante. Genótipos que apresentam maior capacidade antioxidante, tanto enzimática (maior atividade de enzimas, por exemplo, dismutase do superóxido, catalase, peroxidase do ascorbato e redutase da glutationa) como não enzimática (glutationa e ascorbato), tendem a ser mais tolerantes à seca. Essa alta capacidade antioxidante confere maior proteção celular, principalmente da maquinaria fotossintética e manutenção da área foliar, que resulta, consequentemente, em maior produção, mesmo em condições de deficiência hídrica mais severa (Fritsche-Neto \& Borém, 2011).

Em âmbito celular, a resposta adaptativa mais marcante das plantas submetidas ao déficit hídrico é o ajustamento osmótico, que se caracterizam pelo aumento líquido de solutos nas células, os chamados osmólitos estáveis, que compreende a prolina, os álcoois de açúcar, por exemplo, o sorbitol e manitol, dentre outros. $\mathrm{O}$ ajuste osmótico promove a manutenção da turgidez celular em potenciais hídricos muitos negativos, o que permite a manutenção do processo de alongamento celular, além de maior condutância estomática, possibilitando maximização do processo fotossintético, acarretando maior acúmulo de biomassa (Fritsche-Neto \& Borém, 2011). Existem outros mecanismos que conferem à planta capacidade de resistir à seca, a exemplo do crescimento e expansão do sistema radicular, mecanismo de reservas nutritivas da planta ou mesmo através de mecanismos morfológicos da espécie que reduz a perda de água (Fritsche-Neto \& Borém, 2011; Simova-Stoilova et al., 2016; Taiz \& Zeiger, 2009).

Uma característica que confere a planta habilidade de resistir à seca é a alocação de fotoassimilados para crescimento e expansão do sistema radicular em detrimento da parte aérea, como forma de absorver água das camadas profundas do solo (Fritsche-Neto \& Borém, 2011). Essa estratégia ocorre, principalmente, no início do crescimento de plantas xerófilas, sobretudo na fase de plântula. Outro exemplo de importância é o sistema radicular da palma forrageira, que possui raízes absorventes que são produzidas continuamente pela planta na tentativa de absorver umidade superficial do solo, principalmente nas camadas sub superficiais, de 20 a 30 cm (Edvan et al., 2013; Santos et al., 2017).

Sobre mecanismos de reservas nutritivas, existem plantas que armazenam substâncias nutritivas em rizomas, a exemplo do capim buffel e outras em xilopódios, a exemplo do umbuzeiro (Duque, 2004). Além disso, existem plantas lactíferas, a exemplo de $C$. procera, que possui em sua seiva compostos provenientes do metabolismo primário (por exemplo, carboidratos e lipídios) (Almeida et al., 2018), que funcionam como substâncias de reserva e que são degradadas durante o período de seca, para permitir o crescimento e sobrevivência da planta. Dentre os mecanismos morfológicos que reduz a perda de água em plantas, destaca-se a presença de folhas com cutícula espessa, com presença de cerosidade e que se movimentam de modo a diminuir a superfície exposta à radiação (Simova-Stoilova et al., 2016; Taiz \& Zeiger, 2009), C. procera é um exemplo de planta com essas características. Além disso, existem plantas que reduzem a perda de água durante a transpiração, em função da menor área foliar, do número de estômatos, do tamanho do poro estomático ou devido ao controle da condutância estomática (FritscheNeto \& Borém, 2011; Simova-Stoilova et al., 2016; Taiz \& Zeiger, 2009).

Portanto, é necessário conhecer as estruturas da planta, as características agronômicas do vegetal para compreender os mecanismos de resistência à seca e para nortear e subsidiar o melhorista de plantas na tomada de decisão no programa de melhoramento genético. Em função disso, programas de melhoramento genético de plantas podem atuar na seleção de plantas por meio da avaliação de caracteres que estão relacionados com os mecanismos de tolerância e resistência à seca, a exemplo da avaliação da fotossíntese, por meio da leitura de trocas gasosas e fluorescência de clorofila (Graciano et al., 2016), através de características morfológicas, do sistema radicular, da eficiência no uso da água e de variáveis bioquímicas, para avaliar a atividade do sistema antioxidante e o ajustamento osmótico de genótipos 
(Fritsche-Neto \& Borém, 2011), ou por meio de técnicas modernas, como análise proteômica, que permitem uma visão mais profunda dos genótipos com resistencia à seca (Simova-Stoilova et al., 2016).

\section{Melhoramento genético da palma forrageira}

A palma forrageira (Opuntia spp.) é a principal planta xerófila cultivada no Nordeste brasileiro e o programa de melhoramento genético dessa cultura é uma ferramenta necessária para obtenção de novas variedades, com maior potencial de produção, visando atender as necessidades dos pecuaristas do Semiárido brasileiro.

Programas de melhoramento genético da palma têm sido desenvolvidos em países como Itália, México, Brasil e Estados Unidos. No Brasil o Instituto Agronômico de Pernambuco (IPA) é a instituição pioneira nas pesquisas com melhoramento de palma voltada para a produção de forragem e possui um BAG da cultura na Estação Experimental de Arcoverde-PE, com 1417 acessos, sendo 1061 clones gerados da palma gigante, com polinização não controlada; 171 clones gerados da palma miúda, com polinização não controlada; 159 clones oriundos da Universidade de Chapingo no México; 17 clones cedidos pelo CPATSA, oriundos de vários países; cinco clones provenientes do Rio Grande do Norte; quatro clones introduzidos de Petrolina (Inglese et al., 2017).

Em geral, o programa de melhoramento possui etapas distintas, que envolve o cultivo, avaliação e caracterização agronômica de acessos do BAG, para subsidiar os estudos de diversidade genética e otimizar o processo de seleção clonal. Os genótipos selecionados podem participar de ensaios de competição, podendo atingir a função principal do programa que é proceder o registro de cultivares no Ministério da Agricultura Pecuária e Abastecimento (MAPA) com base na regulamentação específica. Também é possível fazer uso de outras estratégias no programa de melhoramento da cultura, como por exemplo: introdução de germoplasma; teste de progênie; técnicas de biotecnologia (uso de marcador molecular, estudos de expressão gênica, cultura de tecidos); indução de mutação; indução a poliploidia in vitro; hibridação, entre outras, como forma de ampliar a base genética da cultura e obter novos genótipos para serem utilizados como opção dentro do programa de melhoramento genético da cultura (Fritsche-Neto \& Borém, 2011).

\section{Melhoramento genético do capim buffel}

As gramíneas nativas da Caatinga, em geral, são plantas xerófilas, classificadas como efêmeras, pois são plantas cujo ciclo vegetativo não ultrapassa algumas semanas ou meses, que aproveitam a estação chuvosa para completar seu ciclo fenológico, ou seja, germinam, crescem, florescem e produzem sementes rapidamente, de modo que conseguem completar todo o seu desenvolvimento fenológico antes que o teor de umidade do solo caia a níveis que possam causar-lhes dano (Duque, 2004; Prisco, 1986). Portanto, são plantas que possuem habilidade de fugir da seca, onde completam todo o ciclo fenológico no período chuvoso e desaparecem, posteriormente, com a chegada da seca. Como exemplo de gramíneas nativas da Caatinga, destaca-se o capim panasco (Aristida adscensionis, Linn.) e o capim mimoso (Anthephora hermaphrodita, Kuntze) (Duque, 2004).

Apesar do potencial forrageiro das gramíneas nativas da Caatinga, o capim buffel (Cenchrus ciliaris L.), gramínea originária da África, Índia e Indonésia, amplamente cultivada em regiões tropicais e subtropicais em todo o mundo é uma planta perene, tolerante à seca, que apresenta alta resistência ao déficit hídrico, sendo uma das gramíneas forrageira mais adequada para o Semiárido brasileiro (Bruno et al., 2017; Moreira et al., 2015). Portanto, explorar seu germoplasma, ou de espécies do mesmo gênero, pode contribuir para a seleção de genótipos com potencial forrageiro, adaptados as condições climáticas regionais (Bruno et al., 2017).

Dentre as pesquisas realizadas no programa de melhoramento da cultura, destaca-se a caracterização agronômica de acessos (Bruno et al., 2017; Jorge et al., 2008; Moreira et al., 2015), com base na altura (Silva et al., 1987) e em análise bromatológica (Silva et al., 1987), além de estudos de diversidade genética (Burson et al., 2015), obtenção de genótipos sexuais para reprodução (Quiroga et al., 2013), determinação da ploidia de acessos por citometria de fluxo (Burson et al., 2012) e estudos de variabilidade morfogenética e ecotípica para resistência à seca no deserto de Cholistan, Paquistão (Arshad et al., 2007; Mansoor et al., 2002). No Brasil a Embrapa Semiárido possui um BAG de Cenchrus 
e conta com 117 acessos oriundos de diferentes Unidades da Embrapa (Gado de Corte, Recursos genéticos e Biotecnologia), de instituições estrangeiras (Commonwealth Scientific and Industrial Research Organisation - CSIRO, Indian Agricultural Research Institute - IARI, National Agricultural Research System - NARS, Texas A \& M University, USA) e de coletas feitas na Paraíba, Pernambuco, Bahia, Sergipe e São Paulo.

Um dos fatores limitantes no programa de melhoramento da cultura é a reprodução da espécie, conhecida genericamente como apomixia. Neste tipo de reprodução, o embrião se desenvolve no ovário a partir de uma célula somática do óvulo, ocorrendo à formação de sementes férteis, sem haver a união do gameta feminino com o masculino, como ocorre na reprodução sexual (Gauer \& Cavalli-Molina, 2000). Dessa forma, as plantas oriundas de sementes apomíticas são geneticamente idênticas à planta mãe, impedindo assim a segregação de genes, dificultando a prática de seleção e a realização da hibridação. Apesar dessa característica que dificulta o melhoramento da cultura, Ayerza (1995) destaca que a apomixia do capim buffel é do tipo facultativa e é controlada por apenas dois genes e que se pode efetuar o cruzamento entre tipos sexuais. Portanto, a seleção de genótipos sexuais no programa de melhoramento da cultura, torna-se uma estratégia importante de ampliar a base genética da cultura, na tentativa de desenvolver novos genótipos via hibridação para o Semiárido brasileiro.

O capim buffel possui características que poderiam ser melhoradas, com ganhos genéticos expressivos de produção. Destas, destaca-se a ocorrência de dormência em sementes, onde o programa de melhoramento da cultura pode atuar na obtenção e seleção de genótipos com maior potencial fisiológico de sementes, ou seja, com maior vigor e percentagem de germinação. Além disso, Moreira et al. (2015) destacam que as próximas ações desenvolvidas no BAG de Cenchrus da Embrapa Semiárido são: ampliar a variabilidade existente e buscar fontes sexuais para obtenção de novas cultivares com tolerância a fatores bióticos e abióticos.

Além do melhoramento tradicional, outras ferramentas podem ser utilizadas no programa de melhoramento da cultura, a exemplo de técnicas de biotecnologia (uso de marcador molecular, estudos de expressão gênica, cultura de tecidos); indução de mutação; indução a poliploidia in vitro, entre outras (Fritsche-Neto \& Borém, 2011), como forma de ampliar a base genética da cultura e obter novos genótipos com maior potencial forrageiro ou com maior tolerância a estresse hídrico e salino, visando atender o perfil das diferentes propriedades rurais do Semiárido brasileiro, principalmente, no tocante as baixas precipitações.

\section{Melhoramento genético do algodão mocó}

O algodão mocó (Gossypium hirsutum L. r. marie galante Hutch) é outra espécie de planta que possui potencial para produção de forragem no Semiárido brasileiro, principalmente, em função de ser uma planta xerófila perene, permanece verde nos períodos de seca, como também por ser uma planta domesticada. É conhecido o potencial forrageiro da cultura, pois durante décadas o algodão mocó foi a principal cultura geradora de renda dos produtores rurais do Nordeste, principalmente, nas áreas mais secas do sertão, a exemplo da região do Seridó do Rio Grande do Norte. O mocó era a principal planta forrageira do Semiárido, em virtude de sua produção de fitomassa e por ser a reserva alimentar nos períodos de seca (Duque, 2004; Moreira et al., 1989). Por sua vez, Moreira et al. (1989) destacam que a pecuária bovina era viabilizada na região Nordeste, devido o cultivo do algodoeiro mocó, pois na época seca do ano a sua rama era utilizada como alimento para o gado.

Apesar dessas informações, não foi encontrado na literatura estudos do potencial de produção e da composição bromatológica do algodão mocó, talvez devido à extinção do cultivo da espécie no Nordeste, sendo necessárias pesquisas nesse sentido. A cultura tem sito utilizada em pesquisas científicas voltadas para o cultivo do algodão herbáceo, visando à produção de algodão. Dessa forma, levando em consideração a adaptabilidade da cultura ao Semiárido brasileiro e devido à contribuição da espécie a pecuária dessa região durante décadas, torna-se importante o desenvolvimento de um programa de melhoramento genético da cultura visando à produção de forragem. A primeira etapa do programa seria a implantação de um BAG da cultura, que envolve o cultivo de acessos oriundos de diferentes regiões do Semiárido brasileiro, seguido da avaliação e caracterização agronômica, estudo de diversidade genética, para subsidiar a seleção de genótipos com maior potencial forrageiro. Existem outras estratégias a serem desenvolvida no programa de melhoramento genético da cultura, porém, o 
cultivo e seleção de acessos com maior potencial produtivo seria um avanço para a pecuária do Semiárido brasileiro.

\section{Melhoramento genético da flor-de-seda}

Conhecida popularmente no Brasil como flor-de-seda (Calotropis procera (Ait.) W.T. Aiton), possui características importantes que subsidiam seu cultivo para produção de forragem no Semiárido brasileiro. Por conta de sua capacidade de resistir à seca, por ser uma planta perenifólia e devido à suas características agronômicas e bromatológicas (Almeida et al., 2017a; Almeida et al., 2018). É uma espécie que sobrevive aos extremos de aridez em países áridos e semiáridos. O fato de ser uma planta perenifólia, ou seja, permanece verde nos períodos mais secos do ano, torna-se uma opção importante de garantir produção de forragem mesmo em anos com baixas precipitações, bem como favorece a colheita da fitomassa no período seco, época que o produtor rural tem baixo suporte forrageiro e necessita de forragem para suprir a dieta animal (Almeida et al., 2017a; Hassan et al., 2015). C. procera é uma espécie de fácil domesticação, visto ter características agronômicas favoráveis para seu cultivo, a exemplo do potencial fisiológico de sementes e de seu crescimento (Almeida et al., 2017b; OliveiraBento et al., 2015). O potencial forrageiro de $C$. procera tem sido constatado em pesquisas científicas, por conta da produtividade da matéria seca, da produção de biomassa e da composição química, sendo recomendada na alimentação de caprinos, ovinos e bovinos na forma de feno, pois na forma in natura possui toxidez, devido ser uma planta lactífera (Costa et al., 2009).

O látex de $C$. procera possui alto teor de compostos ativos, incluindo glicosídeos cardiotônicos, alcalóides, terpenos, resinas, lípidos, flavonóides, taninos e esteróides (Mohamed et al., 2015). Pesquisadores detectaram a presença de diversos metabólitos secundários em C. procera (Kakkar et al., 2012; Mohamed et al., 2015; Shaker et al., 2010), a exemplo de Melo et al. (2005), em que detectaram a presença das seguintes substâncias ativas em folhas e ramos (glicosídeos flavônicos, glicosídeos cardiotônicos, esteroides, triterpenos e polifenóis). Dentre esses metabólitos secundários, os glicosídeos cardiotônicos são os mais importantes, tendo em vista sua ação tóxica em humanos e animais. São definidos como triterpenos ativos contra herbívoros vertebrados e apresentam um gosto amargo, sendo extremamente tóxicos (Taiz \& Zeiger, 2009). Por sua vez, são divididos em dois grupos, os cardenolídeos e os bufadienolídeos. Os cardenolídeos são encontrados em várias famílias vegetais, especialmente em Apocynaceae. Em C. procera pesquisas descrevem diferentes tipos de cardenolídeos, a exemplo do proceragenin (Akhtar et al., 2015), bem como de outros tipos de cardenolídeos (Mohamed et al., 2015). Sabendo que a variação na constituição química dos metabólitos secundários é controlada geneticamente e levando em consideração que muitas plantas cultivadas importantes têm sido selecionadas por produzir níveis relativamente baixos destes compostos, com a função de torná-las desejáveis como alimento para humanos (Taiz \& Zeiger, 2009), o programa de melhoramento genético de $C$. procera pode atuar com o objetivo de selecionar e desenvolver genótipos com redução da síntese de metabolitos secundários, sobretudo do teor de glicosídeos cardiotônicos, visando a produção de forragem.

Dentre as pesquisas realizadas no programa de melhoramento da cultura, destaca-se a caracterização e seleção precoce de acessos (Almeida et al., 2017a), estudo de diversidade genética com base no potencial fisiológico de sementes (Almeida et al., 2017b) e por meio de características agronômicas (Almeida et al., 2018). Neste sentido, outras estratégias no programa de melhoramento genético da espécie podem ser conduzidas, como por exemplo, avaliação do teor de glicosídeo cardiotônico nos acessos de $C$. procera seguido de seleção, hibridação de genitores promissores, uso de ferramentas de biotecnologia, entre outras estratégias.

\section{Melhoramento genético de plantas nativas da Caatinga (mandacarú, feijão-bravo e maniçoba)}

Dentre as principais plantas nativas do bioma Caatinga, o mandacarú (Cereus jamacaru P. DC.) é a espécie largamente utilizada para alimentação animal no Semiárido brasileiro, em períodos de seca. Outra espécie importante para pecuária dessa região e bastante procurada pelos animais nas épocas de escassez de alimentos é o feijão-bravo (Capparis flexuosa L.), em virtude de sua fenologia perenifólia, pois permanece verde nas secas (Almeida Neto et al., 2004; Santana Neto et al., 2015).

A maniçoba (Manihot ssp.) é outra espécie de importância para o Semiárido e que possui potencial de cultivo, principalmente, no período chuvoso, devido sua capacidade de rebrota em baixas 
precipitações e por ser utilizada como forragem conservada na forma de feno e ensilagem (Dantas et al., 2008; Ferreira et al., 2009).

O cultivo do mandacarú, do feijão-bravo e da maniçoba seria uma grande opção de produzir forragem em propriedades rurais do Nordeste, sendo uma estratégia de convivência com à seca, principalmente para regiões com histórico de ocorrência de baixas precipitações. Apesar da importância e do potencial forrageiro dessas espécies, a exploração desses recursos genéticos ocorre de forma extrativista, ou seja, em plantas com ocorrência natural na Caatinga, sendo necessário, portanto, a domesticação de genótipos dessas espécies. O fato de não existir uma variedade de mandacarú, feijão-bravo e maniçoba domesticada, ou seja, que tenha características agronômicas reconhecidas, principalmente as de produção, torna-se arriscado o cultivo dessas culturas em grande escala, em função dos custos de produção e da resposta de crescimento do genótipo propagado.

Sendo assim, torna-se necessário o início do programa de melhoramento genético dessas culturas, com objetivo central de catalogar os materiais promissores, sendo a forma inicial de se desenvolver o cultivo dessas espécies. É notável a existência de variabilidade genética nas espécies, principalmente quando se observa as características morfológicas existentes, com plantas de coloração distinta, com variações no tamanho e divergências na forma de crescimento. Existem plantas de rápida brotação, outras com crescimento mais lento, sendo, portanto, fundamental a caracterização e seleção de genótipos promissores para produção de forragem.

Dessa forma, a primeira etapa seria a implantação de um BAG dessas espécies, que envolve o cultivo de acessos oriundos de diferentes regiões do Semiárido brasileiro, seguido da avaliação, caracterização agronômica, bromatológica, estudo de diversidade genética, para subsidiar a seleção de genótipos com maior potencial forrageiro. Existem outras estratégias a serem desenvolvidas no programa de melhoramento genético dessas espécies, porém, o cultivo e seleção de genótipos com maior potencial produtivo seria um avanço para domesticação dessas culturas no Semiárido brasileiro.

\section{Conclusões}

As principais plantas forrageiras xerófilas indicadas para cultivo em áreas com registro histórico de baixas precipitações no Semiárido brasileiro são palma forrageira (Opuntia spp.) e capim buffel (Cenchrus ciliaris L.), além do algodão mocó (Gossypium hirsutum L. r. marie galante Hutch), flor-deseda (Calotropis procera (Ait.) W.T. Aiton), mandacarú (Cereus jamacaru P. DC.), feijão-bravo (Capparis flexuosa L.) e maniçoba (Manihot ssp.), que possuem potencial de serem cultivadas para produção de forragem.

A execução de programas de melhoramento genético dessas culturas xerófilas torna-se uma ferramenta necessária para cultivo, domesticação de materiais silvestres e obtenção de novas variedades, com maior potencial de produção e com a função de elevar a renda das propriedades rurais do Semiárido brasileiro.

\section{Referências bibliográficas}

Akhtar, S., Ismail, T., Fraternale, D. \& Sestili, P. (2015). Pomegranate peel and peel extracts: Chemistry and food features. Food Chemistry, 174417-425. doi: https://doi.org/10.1016/j.foodchem.2014.11.035.

Almeida, I. V. B., Neder, D. G., Batista, F. R. C. \& Dutra, W. F. (2017a). Characterization and early selection of silk blossom (Calotropis procera) genotypes with forage potential. Revista Caatinga, 30(3):794-801.

Almeida, I. V. B., Ramos, J. P. C., Dutra, W. F., Bruno, R. d. L. A. \& Alves, E. U. (2017b). Genetic diversity among Calotropis procera (Aiton) WT Aiton genotypes according to seed physiological quality. Revista Caatinga, 30(4):912-919.

Almeida, I. V. B., Rêgo, M. M., Batista, F. R. C., Rêgo, E. R. \& Bruno, R. L. A. (2018). Genetic variability among accessions of Calotropis procera based on agronomic characters. Journal of Experimental Agriculture International, 251-12. 
Almeida Neto, J. A., Cruz, R. S., Alves, J. M. \& Moura, M. (2004). Balanço energético de ésteres metílicos e etílicos de óleo de mamona. In: I Congresso Brasileiro de Mamona. Energia e Sustentabilidade.

Andrade, A. P., Costa, R. G., Santos, E. M. \& Silva, D. S. (2010). Produção animal no semiárido: o desafio de disponibilizar forragem, em quantidade e com qualidade, na estação seca. Tecnologia e Ciência Agropecuária, 4(4):1-4.

Andrade, A. P., Souza, E. S., Silva, D. S., Silva, I. F. \& Lima, J. R. S. (2006). Produção animal no bioma caatinga: Paradigmas dos' Pulsos-Reservas'. Revista Brasileira de Zootecnia, 35(1):138-155.

Arshad, M., Ashraf, M. Y., Ahmad, M. \& Zaman, F. (2007). Morpho-genetic variability potential of Cenchrus ciliaris L. from Cholistan desert, Pakistan. Pakistan Journal of Botany, 39(5):1481-1488.

Ayerza (1995)

Bruno, L. R. G. P., Antonio, R. P., Assis, J. G. A., Moreira, J. N. \& Lira, I. C. d. S. A. (2017). Buffel grass morphoagronomic characterization from cenchrus germplasm active bank. Revista Caatinga, 30(2):487-495.

Burson, B. L., Actkinson, J. M., Hussey, M. A. \& Jessup, R. W. (2012). Ploidy determination of buffel grass accessions in the USDA National Plant Germplasm System collection by flow cytometry. South African Journal of Botany, 7991-95.

Burson, B. L., Renganayaki, K., Dowling, C. D., Hinze, L. L. \& Jessup, R. W. (2015). Genetic diversity among pentaploid Buffelgrass accessions. Crop Science, 55(4):1637-1645.

Costa, A. M., Spehar, C. R. \& Sereno, J. R. B. (2012). Conservação de recursos genéticos no Brasil. (8570350376). Brasília, DF, Brasil: EMBRAPA.

Costa, R. G., Medeiros, A. N., Alves, A. R. \& Medeiros, G. R. (2009). Perspectivas de utilização da flor-de-seda (Calotropis procera) na produção animal. Revista Caatinga, 22(1):1-9.

Dantas, F. R., Araújo, G. G. L., Silva, D. S., Pereira, L. G. R., Gonzaga Neto, S. \& Tosto, M. S. L. (2008). Composição química e características fermentativas de silagens de maniçoba ("Manihot" sp.) com percentuais de co-produto de vitivinícolas desidratado. Revista Brasileira de Saúde e Produção Animal, 9(2):247-257.

Duque, J. G. (2004). O Nordeste e as lavouras xerófilas. Fortaleza, Ceará, Brasil: Banco do Nordeste do Brasil.

Edvan, R. L., Fernades, P. D., Carneiro, M. S. S., Neder, D. G., Araujo, J. S., Andrade, A. P. \& Souto Filho, L. T. (2013). Acúmulo de biomassa e crescimento radicular da palma forrageira em diferentes épocas de colheita. Revista Acadêmica Ciência Animal, 11(4):373-381.

Ferreira, A. L., Silva, A. F., Pereira, L. G. R., Braga, L. G. T., Moraes, S. A. d. \& Araújo, G. G. L. (2009). Produção e valor nutritivo da parte aérea da mandioca, maniçoba e pornunça. Revista Brasileira de Saúde e Produção Animal, 10(1):129-136.

Fritsche-Neto, R. \& Borém, A. (2011). Melhoramento de plantas para condições de estresses abióticos. Viçosa, Minas Gerais, Brasil: Editora da Universidade Federal de Viçosa.

Gauer, L. \& Cavalli-Molina, S. (2000). Apomixia: um método alternativo para a produção de sementes em plantas. Pesquisa Agropecuária Brasileira, 6(1):157-170.

Graciano, E. S. A., Santos, H. R. B. \& Nogueira, R.J.M.C. (2016). Trocas gasosas, eficiência fotoquímica e pigmentos fotossintéticos de cultivares de amendoim sob deficiência hídrica no solo. Brazilian Journal of Applied Technology for Agricultural Science, 9, 1, 27-36.

Hassan, L. M., Galal, T. M., Farahat, E. A. \& El-Midany, M. M. (2015). The biology of Calotropis procera (Aiton) WT. Trees, 29(2):311-320.

Inglese, P., Mondragon, C., Nefzaoui, A. \& Saenz, C. (2017). Crop ecology, cultivation and uses of cactus pear. Roma, Itália: Food and Agriculture Organization of the United Nations.

Jorge, M. A. B., Van de Wouw, M., Hanson, J. \& Mohammed, J. (2008). Characterisation of a collection of buffel grass (Cenchrus ciliaris). Tropical Grasslands, 42(1):27-39.

Kakkar, A., Verma, D. R., Suryavanshi, S. \& Dubey, P. (2012). Characterization of chemical constituents of Calotropis procera. Chemistry of Natural Compounds, 48(1):155-157. 
Kitahata, N., Han, S.-Y., Noji, N., Saito, T., Kobayashi, M., Nakano, T., . . Matsumoto, S. (2006). A 9-cis-epoxycarotenoid dioxygenase inhibitor for use in the elucidation of abscisic acid action mechanisms. Bioorganic \& Medicinal Chemistry, 14(16):5555-5561.

Lima, G. F. C., Silva, J. G. M., Aguiar, E. M. \& Teles, M. M. (2010). Reservas forrageiras estratégicas para a pecuária familiar no semiárido: palma, fenos e silagem. EMPARN, 81-53.

Mansoor, U., Hameed, M., Wahid, A. \& Rao, A. (2002). Ecotypic variability for drought resistance in Cenchrus ciliaris L. germplasm from Cholistan Desert in Pakistan. International Journal of Agriculture and Biology, 4(3):392-397.

Melo, M. M., Vaz, F. A., Gonçalves, L. C. \& Saturnino, H. M. (2005). Estudo fitoquímico da Calotropis procera Ait., sua utilização na alimentação de caprinos: efeitos clínicos e bioquímicos séricos. Revista Brasileira de Saúde e Produção Animal, 2(1):15-20.

Mohamed, N. H., Liu, M., Abdel-Mageed, W. M., Alwahibi, L. H., Dai, H., Ismail, M. A., . . Zhang, L. (2015). Cytotoxic cardenolides from the latex of Calotropis procera. Bioorganic \& Medicinal Chemistry Letters, 25(20):4615-4620.

Moreira, J., Freire, E. C., Santos, R. F. \& Barreiro Neto, M. (1989). Algodoeiro mocó: uma lavoura ameaçada de extinção. (0103-0205). Brasília, DF, Brasil: EMBRAPA.

Moreira, J. A. S., Fagundes, J. L., Mistura, C., Lemos, N. L. S., Moreira, J. N., Backes, A. A., . . Moreira, A. L. (2015). Morphogenetical, structural and access to productive buffel grass. Semina: Ciências Agrárias, 36(1):391-400.

Oliveira-Bento, S. R. S., Torres, S. B., Bento, D. A. V., Silva, B. K. A., Dantas, F. J. C. \& Melo, V. C. (2015). Armazenamento de sementes de flor-de-seda [Calotropis procera (Aiton) WT Aiton]. Revista Caatinga, 28(1):39-47.

Prisco, J. T. (1986). Possibilidades de exploração de lavouras xerófilas no semi-árido brasileiro. Pesquisa Agropecuária Brasileira, 21(4):333-342.

Quiroga, M., Grunberg, K., Ribotta, A., Colomba, E. L., Carloni, E., Tommasino, E., . . Griffa, S. (2013). Obtaining sexual genotypes for breeding in buffel grass. South African journal of botany, 88118-123.

Ramos, S. R. R., Queiroz, M. A. \& Pereira, T. N. S. (2007). Recursos genéticos vegetais: manejo e uso. Magistra, 19265-273.

Santana Neto, J. A., Castro Filho, E. S. \& Araújo, H. R. (2015). Potencial das cactáceas como alternativa alimentar para ruminantes no semiárido. Nutritime Revista Eletrônica, 124426-4434.

Santos, M. R., Silva, A. J. P., Fonseca, V. A., Campos, A. R. F. \& Lisboa, M. A. (2017). Irrigação na palma forrageira. Informe Agropecuário, 38(296):76-90.

Seki, M., Umezawa, T., Urano, K. \& Shinozaki, K. (2007). Regulatory metabolic networks in drought stress responses. Current Opinion in Plant Biology, 10(3):296-302.

Shaker, K. H., Morsy, N., Zinecker, H., Imhoff, J. F. \& Schneider, B. (2010). Secondary metabolites from Calotropis procera (Aiton). Phytochemistry Letters, 3(4):212-216.

Silva, C. M. M. S., Oliveira, M. C. \& Severino, G. (1987). Avaliação da produtividade de treze cultivares de capim buffel, na região semi-árida de Pernambuco. Pesquisa Agropecuária Brasileira, 22(5):513520.

Simova-Stoilova, L., Vassileva, V. \& Feller, U. (2016). Selection and breeding of suitable crop genotypes for drought and heat periods in a changing climate: Which morphological and physiological properties should be considered? Agriculture, 6(26):1-19.

Taiz, L. \& Zeiger, E. (2009). Fisiologia vegetal (Vol. 4). Porto Alegre, Brasil: Artmed.

Recebido: 14 de maio, 2019.

Aprovado: 13 de junho, 2019.

Publicado: 14 de agosto, 2019.

Licenciamento: Este artigo é publicado na modalidade Acesso Aberto sob a licença Creative Commons Atribuição 4.0 (CC-BY 4.0), a qual permite uso irrestrito, distribuição, reprodução em qualquer meio, desde que o autor e a fonte sejam devidamente creditados. 